\title{
Informal regionalization of pediatric fracture care in the Greater Toronto Area: a retrospective cross-sectional study
}

\author{
Daniel Pincus MD, Steven Morrison BSc, Martin F. Gargan MA(Oxon) BM BCh, \\ Mark W. Camp MD MSc
}

\section{Abstract}

Background: Operative management of pediatric fractures is an expected competency in the specialty of Orthopedic Surgery. However, specialized pediatric centres may be providing care for increasing numbers of patients with fractures previously treated at community hospitals. The primary objective of this study was to examine trends in presentation of children with fractures to a specialized pediatric centre.

Methods: We performed a detailed chart review to examine trends in presentation of children aged 14 years or less with supracondylar humerus or femur fractures to a specialized pediatric centre (Hospital for Sick Children, Toronto) from anywhere in the Greater Toronto Area between Apr. 1, 2008, and Mar. 31, 2015. Consecutive patients admitted to hospital and requiring operative intervention for a supracondylar humerus or femur fracture were considered. We calculated changes in operation incidence rates per year using multivariable negative binomial regression models.

Results: A total of 945 children with supracondylar humerus fractures and 421 with femur fractures underwent operative intervention during the study period. The baseline characteristics of the 2 groups were similar irrespective of which year fixation occurred. The annual incidence rate of supracondylar humerus fractures increased from 108 to 169 (56.5\%) over the study period, at an adjusted rate of $7.5 \%$ per year (adjusted incidence rate ratio [IRR] 1.075, 95\% confidence interval $[\mathrm{Cl}] 1.072-1.079, p<0.001$ ). The annual incidence rate of femur fractures increased from 49 to 69 (40.8\%), at an adjusted rate of 5.3\% per year (adjusted IRR $1.053,95 \% \mathrm{Cl} 1.044-1.062, p<0.001)$. Significant increases were observed independent of fracture classification, stabilization method, whether patients were transferred from an outside hospital or presented directly, patient geographic location or the season in which the fracture occurred.

Interpretation: Adjusted annual incidence rates of supracondylar humerus and femur fractures increased significantly over the study period. Further work is needed to assess the clinical impact of informal regionalization of care and to determine whether the phenomenon occurs in other specialties.

upracondylar humerus and femur fractures are the 2 most common operatively treated pediatric fractures in Ontario. ${ }^{1}$ Operative management of pediatric fractures is an expected competency within the Objectives of Training in the specialty of Orthopedic Surgery for the Royal College of Physicians and Surgeons of Canada. ${ }^{2}$ However, anecdotal evidence in our region indicates that specialized pediatric centres are providing care for increasing numbers of patients with fractures previously treated in community hospitals. In contrast to "formal regionalization," ${ }^{3-6}$ this process is occurring informally, without clear coordination or agreement between providers. ${ }^{7}$

The primary objective of this study was to examine trends in presentation of children with fractures to a specialized pediatric centre from anywhere in the Greater
Toronto Area. We hypothesized that patients were increasingly arriving from several geographic areas within the Greater Toronto Area, both by direct presentation and outside hospital transfer, and after adjustment for population changes and covariates that may have influenced these rates.

\section{Competing interests: None declared.}

This article has been peer reviewed.

Correspondence to: Daniel Pincus, d.pincus@utoronto.ca

CMAJ Open 2017. DOI:10.9778/cmajo.20160156 


\section{Methods}

\section{Setting}

We conducted a retrospective, serial, cross-sectional study at The Hospital for Sick Children (SickKids), Toronto. We identified consecutive patients admitted to the hospital and requiring operative intervention for a supracondylar humerus or femur fracture between Apr. 1, 2008, and Mar. 31, 2015, using the hospital's Surgical Information Systems database (SIS 4.7.10a). ${ }^{8}$ We chose the date for the beginning of the study period on the basis of when recording detailed data regarding every surgical case became routine (Appendix 1, available at www.cmajopen.ca/content/5/2/ E468/suppl/DC1).

\section{Population}

Patients aged 14 years or less requiring operative intervention for a supracondylar humerus or femur fracture during the study period were eligible for inclusion. Fractures needing pediatric orthopedic specialist referral were excluded and were operationalized as being associated with bone cysts, abnormal lesions or nonaccidental injury, or referred for revision surgery or treatment failure after initial nonoperative management. Look-back for exclusion criteria occurred to Jan. 1, 2000. Geographic boundaries of the Greater Toronto Area (population 6.054 million in 2011) were defined by the borders of Local Health Integrated Networks (LHINs) 5, 6, 7, 8 and 9; patients residing outside these regions were excluded owing to their low number.

\section{Chart review}

Detailed chart abstraction was performed by medical and orthopedic trainees (D.P., S.M. and 2 other trainees) and was reviewed by 2 pediatric orthopedic surgeons (M.F.G. and M.W.C.).

\section{Outcomes}

Annual incidence rates of supracondylar humerus and femur fractures presenting to SickKids constituted the primary outcome. The number of operations performed each fiscal year were population-adjusted to account for population changes during the study period. Specifically, all rates were standardized to the 2011 Greater Toronto Area population aged less than 14 years (2011 Canadian census). We compared these rates to the total annual number of surgical cases of supracondylar humerus fracture treated at community hospitals and at the 4 other specialized pediatric centres in Ontario. These data were obtained from a previously published populationbased cohort (Appendix 1). ${ }^{9}$

We mapped patients to their location of residence or "dissemination area" using ArcGIS 10.2 software (Esri). Dissemination areas are the smallest geographic unit for which census population data are available in Canada. We used the bar chart option to create bar maps, where the height of the bar represents the total sum of fractures by year in each LHIN.

\section{Main exposure and covariates}

The primary exposure was the fiscal year in which surgery occurred. We also measured several covariates that may potentially motivate pediatric orthopedic specialist referral. We assessed the need for dedicated pediatric anesthesia using the American Society of Anesthesiologists score and the presence of patient comorbidity (yes/no) listed on hospital admission records. Injury-specific variables included 1) Gartland classification for supracondylar humerus fractures (type II v. type III or IV), ${ }^{10}$ 2) femur stabilization method (fixation $v$. spica casting), 3) injury energy, including open fractures, 4) associated fracture, neurovascular injury or compartment syndrome and 5) requirement for reoperation (up to Mar. 31, 2016). Admission characteristics included 1) being transferred directly from an outside hospital, 2) surgery occurring during summer months (April-September) or after hours (between $5 \mathrm{pm}$ and 7 am during the week or any time over the weekend), 3) time elapsed from emergency department presentation to surgery and 4) duration of surgery (total time elapsed in the operating room).

\section{Statistical analysis}

We calculated descriptive statistics for all variables. Age was normally distributed and was expressed with other continuous variables as mean and standard deviation (SD). Categorical variables were calculated as proportions. We assessed whether baseline characteristics changed over time using the CochranArmitage trend test for categorical variables and simple linear regression for continuous variables. We calculated changes in incidence rates of supracondylar humerus and femur surgery using incidence rate ratios (IRRs) for 1-year increments spanning each fiscal year. To address potential temporal confounding by demographic, injury and admission characteristics that may have differentially motivated pediatric orthopedic specialist referral by year, we calculated adjusted IRRs using 2 multivariable negative binomial regression models. Predictors included in the multivariable model for supracondylar humerus operation rates were age, sex, American Society of Anesthesiologists score, patient LHIN, Gartland classification, open fracture, presence of preoperative nerve palsy, associated fracture, surgery in summer and after-hours surgery. Predictors included in the multivariable model for femur operation rates were age, sex, presence of comorbidity, patient LHIN, injury severity (high/low energy), stabilization method, open fracture, associated fracture, surgery in summer and afterhours surgery. IRRs and $95 \%$ confidence intervals (CIs) are reported.

\section{Sensitivity analyses}

We examined for the presence of effect modification in subgroup analyses stratified according to 1) patient transfer status (outside transfer/direct presentation), 2) Gartland classification, 3) femur stabilization method, 4) patient LHIN and $5)$ season of surgery. We performed all statistical analyses using SAS Studio 9.3 University Edition (SAS Institute), and the type I error probability was set at 0.05 for all 2 -sided tests of statistical significance. 


\section{Ethics approval}

The investigation received approval from the research ethics boards at SickKids and Sunnybrook Health Sciences Centre.

\section{Results}

\section{Baseline characteristics}

Of the 1366 patients with fractures who underwent operative intervention between 2008/09 and 2014/15 and met the study inclusion criteria, 945 had supracondylar humerus fractures and 421 had femur fractures (Figure 1). The mean age of the patients with supracondylar humerus fractures was 5.44 (SD 2.52) years, and $52.6 \%$ were boys. The mean age of the patients with femur fractures was 5.53 (SD 4.40) years, and $74.3 \%$ were boys.

Compared to $2008 / 09$, in $2014 / 15$, the mean duration of supracondylar humerus surgery was shorter (69.98 [SD 32.87] $\min$ v. 81.40 [SD 21.51] $\mathrm{min}, p$ for trend $=0.003)$, and a smaller proportion of femur procedures were performed after hours $(39.1 \%$ v. $66.0 \%, p$ for trend $=0.005)$ (Table 1, Table 2$)$. For both supracondylar humerus and femur fractures, the proportion of patients with any comorbidity listed on their admission record increased over the study period ( $p$ for trend $=0.007$ and $<0.001$, respectively). However, the American Society of Anesthesiologists score did not change over time. Other baseline characteristics were similar in both groups, independent of which year fixation occurred.

\section{Outcomes}

\section{Single-centre data}

The annual incidence rate of supracondylar humerus fractures increased by $56.5 \%$ (108 to 169) over the study period, at an adjusted rate of $7.5 \%$ per year (adjusted IRR 1.075 , 95\% CI $1.072-1.079, p<0.001)$. Similarly, the annual incidence rate of femur fractures increased by $40.8 \%$ (49 to 69), at an adjusted rate of $5.3 \%$ per year (adjusted IRR 1.053 , 95\% CI 1.044-1.062, $p<0.001)$.

For both fracture types, patients presented from each LHIN within the Greater Toronto Area, with most being from the Central Toronto LHIN (LHIN 7). In most LHINs, the incidence of fractures increased over time (Figure 2).

\section{Population-based data}

Between 2002 and 2015, 75 different hospitals in Ontario operatively treated supracondylar humerus fractures. During this period, the annual rate of supracondylar humerus fractures treated at SickKids increased significantly, by $10 \%$ per year (IRR 1.104, 95\% CI 1.072-1.138, $p<0.001$ ). In contrast, the annual rate of supracondylar humerus fractures treated in the community decreased significantly, by $4 \%$ per year (IRR $0.963,95 \%$ CI $0.952-0.975, p<0.001)$. The number at other specialized pediatric centres did not change significantly during this period (IRR $1.008,95 \%$ CI $0.992-1.024, p=0.4$ ). In other words, of every 100 supracondylar humerus fractures in Ontario in 2002, 11 were treated at SickKids, 36 at other pediatric centres and 53 in the community. In 2015, of every
100 supracondylar humerus fractures in the province, 40 were treated at SickKids, 35 at other pediatric centres and 25 in the community (Figure 3).

\section{Sensitivity analyses}

Significant increases in adjusted fracture rates were observed independent of the supracondylar humerus fracture classification or femur stabilization method (Table 3, Figure 4). Adjusted supracondylar humerus fracture rates increased independent of whether patients were transferred or presented directly. In contrast, increases in adjusted femur fracture rates were significant only for transferred patients (adjusted IRR 1.060, 95\% CI 0.99-1.13, $p<0.01$ ).

\section{Interpretation}

Between 2008/09 and 2014/15, baseline characteristics of children presenting to SickKids with supracondylar humerus or femur fractures were similar irrespective of which year fixation occurred. The annual incidence rate of supracondylar humerus fractures increased by $56.5 \%$, at an adjusted rate of $7.5 \%$ per year, and the annual incidence rate of femur fractures increased by $40.8 \%$, at an adjusted rate of $5.3 \%$ per year. Significant increases in adjusted fracture rates were observed independent of fracture classification, fracture stabilization method, whether patients were transferred from an outside hospital or presented directly, patient LHIN or the season in which the fracture occurred. In contrast, the annual rate of supracondylar humerus fractures decreased significantly at community hospitals and remained stable at other specialized pediatric centres in the province.

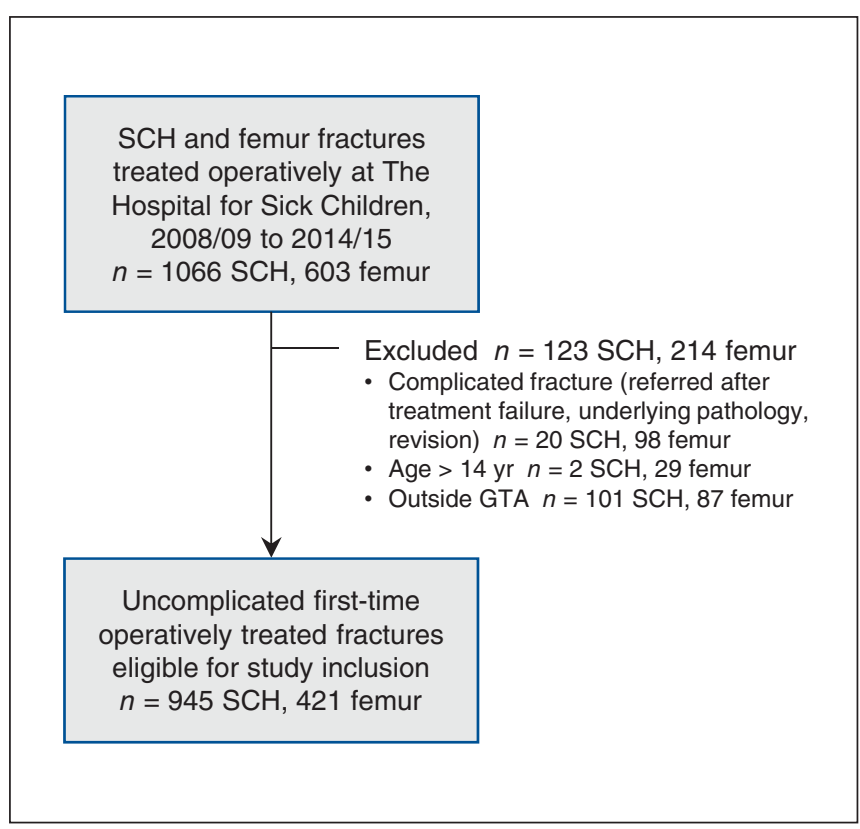

Figure 1: Flow chart showing selection of study patients. GTA = Greater Toronto Area, $\mathrm{SCH}$ = supracondylar humerus. Numbers eligible for study inclusion do not equal total numbers less numbers excluded because exclusions were not sequential (there were overlaps between "complicated fracture", "age >14" and "outside GTA"). 


\begin{tabular}{|c|c|c|c|c|c|c|c|c|c|}
\hline \multirow[b]{2}{*}{ Characteristic } & \multicolumn{8}{|c|}{ Year; no. $(\%)$ of patients ${ }^{*}(n=945)$} & \multirow{2}{*}{$\begin{array}{l}p \text { value } \\
\text { for } \\
\text { trend }\end{array}$} \\
\hline & $\begin{array}{l}2008 / 09 \\
(n=108)\end{array}$ & $\begin{array}{l}2009 / 10 \\
(n=113)\end{array}$ & $\begin{array}{l}2010 / 11 \\
(n=101)\end{array}$ & $\begin{array}{l}2011 / 12 \\
(n=158)\end{array}$ & $\begin{array}{l}2012 / 13 \\
(n=150)\end{array}$ & $\begin{array}{l}2013 / 14 \\
(n=146)\end{array}$ & $\begin{array}{l}2014 / 15 \\
(n=169)\end{array}$ & Missing & \\
\hline \multicolumn{10}{|l|}{ Demographic } \\
\hline Age, mean $\pm S D$, yr & $5.44 \pm 2.47$ & $5.20 \pm 2.54$ & $5.66 \pm 2.78$ & $5.35 \pm 2.42$ & $5.53 \pm 2.55$ & $5.51 \pm 2.50$ & $5.43 \pm 2.47$ & $0(0)$ & 0.7 \\
\hline Female sex & $56(51.9)$ & $64(56.6)$ & $39(39.4)$ & $68(43.6)$ & $63(42.0)$ & $70(48.0)$ & $86(50.9)$ & $4(0.4)$ & 0.6 \\
\hline $\begin{array}{l}\text { American Society of } \\
\text { Anesthesiologists score }\end{array}$ & & & & & & & & $30(3.2)$ & 0.3 \\
\hline-1 & $86(86.9)$ & $96(90.6)$ & $85(87.6)$ & $136(88.3)$ & $129(87.8)$ & $128(87.7)$ & $154(92.8)$ & & \\
\hline-2 & $11(11.1)$ & $9(8.5)$ & $11(11.3)$ & $16(10.4)$ & $17(11.6)$ & $16(11.0)$ & $10(6.0)$ & & \\
\hline-3 & $2(2.0)$ & $1(0.9)$ & $1(1.0)$ & $2(1.3)$ & $1(0.7)$ & $2(1.4)$ & $2(1.2)$ & & \\
\hline $\begin{array}{l}\text { Presence of any } \\
\text { comorbidity }\end{array}$ & $0(0)$ & $0(0)$ & $2(2.0)$ & $3(1.9)$ & 0 & $7(4.8)$ & $5(3.0)$ & $0(0)$ & 0.007 \\
\hline \multicolumn{10}{|l|}{ Injury } \\
\hline Gartland type III/IV & $73(71.6)$ & $67(60.4)$ & $58(57.4)$ & $100(64.1)$ & 89 (59.3) & $96(65.8)$ & $105(62.5)$ & $11(1.2)$ & 0.6 \\
\hline Open fracture & $3(2.8)$ & $1(0.9)$ & $1(1.0)$ & $4(2.6)$ & $2(1.4)$ & $0(0)$ & $2(1.2)$ & $13(1.4)$ & 0.2 \\
\hline Associated injury & $3(2.8)$ & $5(4.4)$ & $8(7.9)$ & $4(2.5)$ & $6(4.0)$ & $3(2.0)$ & $4(2.4)$ & $0(0)$ & 0.2 \\
\hline Preoperative nerve palsy & $24(22.2)$ & $21(19.4)$ & $17(17.4)$ & $22(14.5)$ & $19(12.8)$ & $18(12.4)$ & $34(21.0)$ & $23(2.4)$ & 0.3 \\
\hline Compartment syndrome & $1(0.9)$ & $0(0)$ & $1(1.02)$ & $0(0)$ & $0(0)$ & $0(0)$ & $2(1.2)$ & $14(1.5)$ & 0.8 \\
\hline Vascular compromise & $0(0)$ & $0(0)$ & $2(2.0)$ & $0(0)$ & $0(0)$ & $0(0)$ & $0(0)$ & $13(1.4)$ & 0.3 \\
\hline Reoperation (any reason) & $3(2.8)$ & $0(0)$ & $4(4.0)$ & $2(1.3)$ & $4(2.7)$ & $1(0.7)$ & $4(2.4)$ & $10(1.0)$ & 1.0 \\
\hline \multicolumn{10}{|l|}{ Admission } \\
\hline $\begin{array}{l}\text { Transferred from outside } \\
\text { hospital }\end{array}$ & $89(82.4)$ & $88(77.9)$ & $72(71.3)$ & $120(75.9)$ & $116(77.3)$ & $118(80.8)$ & $127(75.1)$ & $0(0)$ & 0.6 \\
\hline Surgery in summer & $74(68.5)$ & $89(78.8)$ & $75(74.2)$ & $113(71.5)$ & $112(74.7)$ & $102(69.9)$ & $120(71.0)$ & $0(0)$ & 0.6 \\
\hline Surgery after hours & $52(48.1)$ & $59(52.2)$ & $50(49.5)$ & $100(63.3)$ & $86(57.3)$ & $74(50.7)$ & $98(58.0)$ & $0(0)$ & 0.2 \\
\hline $\begin{array}{l}\text { Delay to fixation, mean } \\
\pm \mathrm{SD}, \mathrm{h}\end{array}$ & $13.73 \pm 18.44$ & $12.74 \pm 5.99$ & $11.53 \pm 6.54$ & $13.49 \pm 7.54$ & $12.39 \pm 7.34$ & $12.54 \pm 6.71$ & $11.27 \pm 6.28$ & $31(3.3)$ & 0.1 \\
\hline $\begin{array}{l}\text { Surgical duration, mean } \\
\pm \text { SD, min }\end{array}$ & $81.40 \pm 21.51$ & $81.60 \pm 30.95$ & $86.43 \pm 59.75$ & $85.13 \pm 42.77$ & $81.23 \pm 32.35$ & $78.42 \pm 29.91$ & $69.98 \pm 32.87$ & $4(0.4)$ & 0.003 \\
\hline $\begin{array}{l}\text { Length of stay, mean } \pm \\
\text { SD, d }\end{array}$ & $1.25 \pm 1.08$ & $1.22 \pm 0.41$ & $1.28 \pm 0.70$ & $1.20 \pm 0.40$ & $1.23 \pm 0.43$ & $1.22 \pm 0.47$ & $1.14 \pm 0.48$ & $4(0.4)$ & 0.2 \\
\hline $\begin{array}{l}\text { Cost of index admission, } \\
\text { mean } \pm \text { SD, } \$\end{array}$ & $2560 \pm 1190$ & $2306 \pm 507$ & $2685 \pm 951$ & $2512 \pm 673$ & $2529 \pm 599$ & $2457 \pm 586$ & $2353 \pm 767$ & $4(0.4)$ & 0.2 \\
\hline
\end{tabular}

We also observed that the vast majority (> 70\% every year) of children with fractures treated at SickKids during the study period were transferred from outside hospitals and that significant increases in adjusted fracture rates occurred independent of the complexity of the injury and the type of surgery required. This suggests that practice changes were unlikely the result of inadequate training. Since the median surgeon volume of supracondylar humerus fixation is only 9 cases per year in Ontario, ${ }^{9}$ however, referrals may be selffulfilling over time, with transfers begetting transfers as case volumes and associated technical competence decreases, particularly in the context of increasing specialization. ${ }^{3,11-18}$ Significant increases in rates of direct presentation of patients with supracondylar humerus fractures were also observed, which may reflect parental preference for treatment at a dedicated pediatric centre. In contrast, rates of direct presentation of patients with femur fractures did not increase. These findings are consistent with our clinical experience that parental transport of a child to hospital is more sensible when the injury is to the upper extremity (e.g., supracondylar humerus) as opposed to the femur.

Informal regionalization of care has also been observed in Canada for high-risk cancer surgery. ${ }^{7}$ However, high-risk cancer surgery is not an expected competency for general surgeons without fellowship training, ${ }^{2}$ whereas general orthopedic surgeons are trained to care for children with fractures. In addition, informal regionalization of cancer surgery occurred quite uniformly across Canada. ${ }^{7}$ In contrast, 
Table 2: Baseline characteristics of patients who underwent surgery for femur fracture

\begin{tabular}{|c|c|c|c|c|c|c|c|c|c|}
\hline \multirow[b]{2}{*}{ Characteristic } & \multicolumn{8}{|c|}{ Year; no. $(\%)$ of patients ${ }^{*}(n=421)$} & \multirow{2}{*}{$\begin{array}{l}p \text { value } \\
\text { for } \\
\text { trend }\end{array}$} \\
\hline & $\begin{array}{r}2008 / 09 \\
(n=47)\end{array}$ & $\begin{array}{c}2009 / 10 \\
(n=49)\end{array}$ & $\begin{array}{l}2010 / 11 \\
(n=52)\end{array}$ & $\begin{array}{l}2011 / 12 \\
(n=83)\end{array}$ & $\begin{array}{c}2012 / 13 \\
(n=55)\end{array}$ & $\begin{array}{l}2013 / 14 \\
(n=66)\end{array}$ & $\begin{array}{c}2014 / 15 \\
(n=69)\end{array}$ & Missing & \\
\hline \multicolumn{10}{|l|}{ Demographic } \\
\hline Age, mean $\pm S D$, yr & $5.19 \pm 4.22$ & $6.00 \pm 4.55$ & $5.65 \pm 4.33$ & $5.61 \pm 4.44$ & $6.80 \pm 4.84$ & $4.73 \pm 4.28$ & $4.97 \pm 4.08$ & $0(0)$ & 0.7 \\
\hline Female sex & $14(29.8)$ & $7(14.3)$ & $18(34.6)$ & $20(24.1)$ & $16(29.1)$ & $18(27.3)$ & $15(21.7)$ & $0(0)$ & 0.8 \\
\hline $\begin{array}{l}\text { Presence of any } \\
\text { comorbidity }\end{array}$ & $0(0)$ & $1(2.0)$ & $0(0)$ & $2(2.4)$ & $2(3.6)$ & $8(12.1)$ & $8(11.6)$ & $0(0)$ & $<0.001$ \\
\hline \multicolumn{10}{|l|}{ Injury } \\
\hline $\begin{array}{l}\text { Fixation (v. spica } \\
\text { casting) }\end{array}$ & $15(31.9)$ & $24(49.0)$ & $23(44.2)$ & $38(45.8)$ & $30(54.5)$ & $24(36.4)$ & $29(42.0)$ & $0(0)$ & 0.8 \\
\hline $\begin{array}{l}\text { High-energy } \\
\text { mechanism }\end{array}$ & $46(97.9)$ & $44(89.8)$ & $48(92.3)$ & $81(97.6)$ & $52(94.5)$ & $65(98.5)$ & $69(100.0)$ & $2(0.5)$ & 0.02 \\
\hline Open fracture & $1(2.1)$ & $0(0)$ & $0(0)$ & $1(1.2)$ & $1(1.8)$ & $0(0)$ & $1(1.4)$ & $0(0)$ & 1.0 \\
\hline Associated injury & $1(2.1)$ & $1(2.0)$ & $0(0)$ & $5(6.0)$ & $2(3.6)$ & $5(7.6)$ & $3(4.3)$ & $0(0)$ & 0.1 \\
\hline $\begin{array}{l}\text { Reoperation (any } \\
\text { reason) }\end{array}$ & $3(6.4)$ & $11(22.4)$ & $7(13.5)$ & $16(19.3)$ & $11(20.0)$ & $8(12.1)$ & $2(2.9)$ & $0(0)$ & 0.2 \\
\hline \multicolumn{10}{|l|}{ Admission } \\
\hline $\begin{array}{l}\text { Transferred from } \\
\text { outside hospital }\end{array}$ & $38(80.8)$ & $40(81.6)$ & $46(88.5)$ & $59(71.1)$ & $47(85.4)$ & $48(72.7)$ & $60(87.0)$ & $0(0)$ & 1.0 \\
\hline Surgery in summer & $18(38.3)$ & $28(57.1)$ & $29(55.8)$ & $50(60.2)$ & $30(54.5)$ & $35(53.0)$ & $38(55.1)$ & $0(0)$ & 0.3 \\
\hline Surgery after hours & $31(66.0)$ & $28(57.1)$ & $31(59.6)$ & $43(51.8)$ & $32(58.2)$ & $33(50.0)$ & $27(39.1)$ & $0(0)$ & 0.005 \\
\hline $\begin{array}{l}\text { Delay to fixation, mean } \\
\pm \mathrm{SD}, \mathrm{h}\end{array}$ & $18.72 \pm 26.01$ & $24.13 \pm 58.70$ & $15.30 \pm 8.55$ & $19.77 \pm 14.67$ & $16.55 \pm 12.04$ & $15.65 \pm 10.57$ & $18.68 \pm 22.20$ & $7(1.6)$ & 0.1 \\
\hline $\begin{array}{l}\text { Surgical duration, } \\
\text { mean } \pm S D \text {, min }\end{array}$ & $99.13 \pm 61.61$ & $112.61 \pm 57.52$ & $104.31 \pm 58.65$ & $126.99 \pm 83.65$ & $129.11 \pm 76.35$ & $107.03 \pm 72.10$ & $97.14 \pm 51.33$ & $0(0)$ & 0.003 \\
\hline $\begin{array}{l}\text { Length of stay, mean } \\
\pm \mathrm{SD}, \mathrm{d}\end{array}$ & $2.57 \pm 1.84$ & $3.08 \pm 3.11$ & $2.29 \pm 1.21$ & $3.00 \pm 3.32$ & $2.29 \pm 1.24$ & $2.35 \pm 2.50$ & $2.86 \pm 6.39$ & $0(0)$ & 0.2 \\
\hline $\begin{array}{l}\text { Cost of index } \\
\text { admission, mean } \\
\pm \text { SD, \$ }\end{array}$ & $4152 \pm 2193$ & $4865 \pm 3961$ & $4083 \pm 1843$ & $5541 \pm 7728$ & $4494 \pm 2037$ & $4871 \pm 8029$ & $6139 \pm 17646$ & $0(0)$ & 0.2 \\
\hline
\end{tabular}

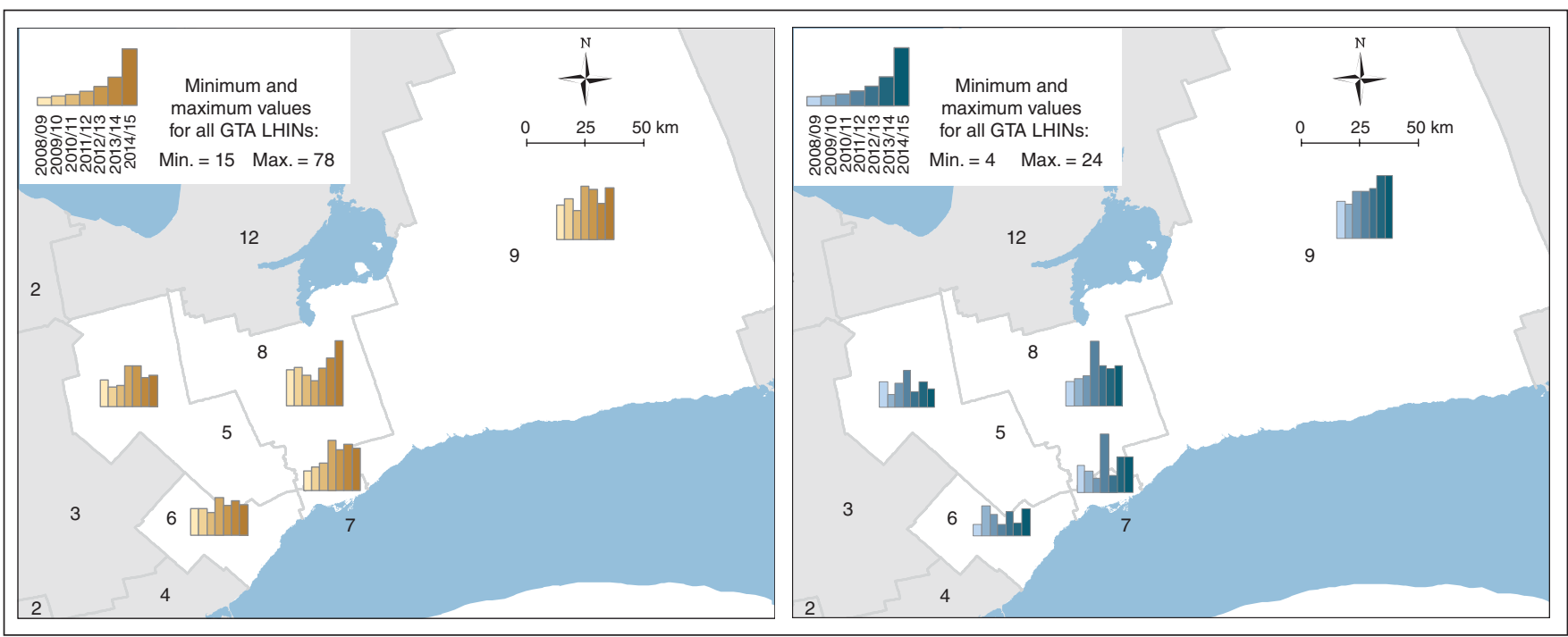

Figure 2: Population-standardized number of supracondylar humerus (left) and femur (right) fractures in the Greater Toronto Area (GTA), 2008/09 to 2014/15. Number standardized to 2011 GTA population aged 14 years or less. Numbers within regions indicate Local Health Integrated Networks (LHINs). Patients presenting from geographic areas outside the GTA LHINs were excluded from all analyses. 


\begin{tabular}{|cc|}
\hline 2002 & 2015 \\
0000000000 & 0000000000 \\
0000000000 & 0000000000 \\
0000000000 & 0000000000 \\
0000000000 & 0000000000 \\
0000000000 & 0000000000 \\
0000000000 & 0000000000 \\
0000000000 & 0000000000 \\
0000000000 & 0000000000 \\
0000000000 & 0000000000 \\
0000000000 & 0000000000 \\
0 & \\
0 & The Hospital for Sick Children \\
O community hospital \\
\hline
\end{tabular}

Figure 3: Proportion of supracondylar humerus fractures in 2002 versus 2015 treated at The Hospital for Sick Children, other specialized pediatric centres and community hospitals.

Table 3: Adjusted fracture rates*

\begin{tabular}{|c|c|}
\hline Fracture type; variable & Adjusted IRR $(95 \% \mathrm{CI})$ \\
\hline \multicolumn{2}{|c|}{ Supracondylar humerus } \\
\hline Overall & $1.075(1.072-1.079)$ \\
\hline Transferred & $1.069(1.065-1.073)$ \\
\hline Direct presentation & $1.075(1.075-1.10)$ \\
\hline Gartland type II & $1.088(1.080-1.097)$ \\
\hline Gartland type III & $1.070(1.064-1.075)$ \\
\hline \multicolumn{2}{|l|}{ Femur } \\
\hline Overall & $1.053(1.044-1.062)$ \\
\hline Transferred & $1.056(1.048-1.065)$ \\
\hline Direct presentation & $1.060(0.99-1.13)$ \\
\hline Spica casting & $1.055(1.037-1.74)$ \\
\hline Fixation & $1.060(1.043-1.69)$ \\
\hline \multicolumn{2}{|c|}{$\begin{array}{l}\text { Note: } \mathrm{Cl}=\text { confidence interval, IRR = incidence rate ratio. } \\
\text { *Supracondylar humerus operation rates were adjusted for age, sex, American } \\
\text { Society of Anesthesiologists score, patient Local Health Integrated Network } \\
\text { (LHIN), Gartland classification, open fracture, presence of preoperative nerve } \\
\text { palsy, associated fracture, surgery in summer and after-hours surgery. Femur } \\
\text { operation rates were adjusted for age, sex, presence of comorbidity, patient } \\
\text { LHIN, injury severity (high/low energy), stabilization method, open fracture, } \\
\text { associated fracture, surgery in summer and after-hours surgery. }\end{array}$} \\
\hline
\end{tabular}

we found that the annual rate of supracondylar humerus fractures remained stable at specialized pediatric centres other than SickKids. In other words, informal regionalization appears to be occurring within the Greater Toronto Area but not elsewhere in the province. Although informal regionalization may be associated with improved outcomes for highrisk cancer surgery, ${ }^{7}$ controversy exists as to whether lower complication rates are related to treatment at academic facilities for pediatric fractures, ${ }^{9,19-21}$ particularly when transfer delays are expected. ${ }^{22}$ In our study, half of the operative cases occurred after hours, and wait times for these procedures did not improve. Since we were unable to measure the time elapsed in transfer from outside hospitals, it is likely that wait times actually increased with informal regionalization in this case. Future work is required to determine whether informal regionalization of pediatric fracture surgery yields benefits ascribed to formal regionalization, which include cost savings and improved quality of care..$^{3-6}$ Also important is that specialized pediatric centres may be increasingly challenged with providing timely care for increasing numbers of patients previously treated in the community. In the absence of dedicated orthopedic trauma operating rooms, the trends observed in the current study may influence the ability of specialized pediatric centres to treat patients with complex needs requiring highly specialized care, which is their mandate. ${ }^{23}$ Our findings therefore may help inform policy, funding and formal integration regarding pediatric fracture care in our region and elsewhere.

\section{Limitations}

The most important limitation of our study of single-centre data is that we could not identify rates of fractures presenting to other institutions. Although we standardized the rates to the population to remove the influence of population changes, we also report the exact number of supracondylar humerus fractures per year in Ontario by hospital type using population-based data. On the other hand, the availability of detailed injury characteristics in our single-centre chart review, such as Gartland classification, and our adjustment for these characteristics in both regression and subgroup analyses allowed us to account for several potential temporal confounders not recorded in Ontario's administrative data. For example, practice patterns would not have been expected to change for Gartland type II or III supracondylar humerus fractures during the study period. Differences in billing practices between specialized pediatric centres and community hospitals may also have influenced the population-based rates described in this study, which used billing codes to identify cases of supracondylar humerus fracture. In addition, although the beginning of the study period was chosen on the basis of when recording consecutive surgical cases became reliable, we recognize that informal regionalization may have started well before 2008. Indeed, the population-based rates of supracondylar humerus fracture indicate that these trends began as far back as 2002. We also cannot explain the large incidence increase in 2011. Since our objective a priori was to describe adjusted rates of fractures presenting to our institution rather than explore a specific occurrence in 2011 or the influence of a specific intervention, we did not conduct a formal time-series analysis.

\section{Conclusion}

Over the period 2008/09 to 2014/15, patients increasingly arrived from several geographic regions within the Greater Toronto Area, both by direct presentation and outside hospital transfer, without formal coordination between providers. Although informal regionalization appears to be 


\section{OPEN}

Research

\section{A) Stratified by transfer status}

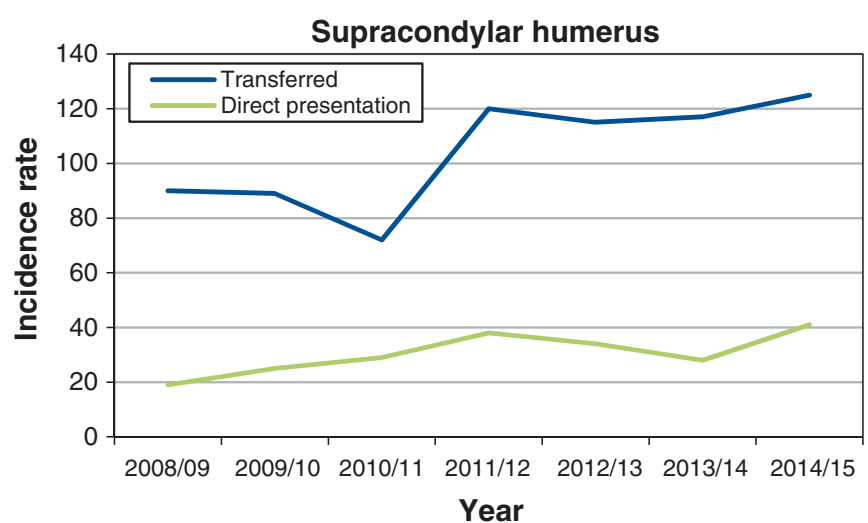

B) Stratified by injury severity/stabilization method

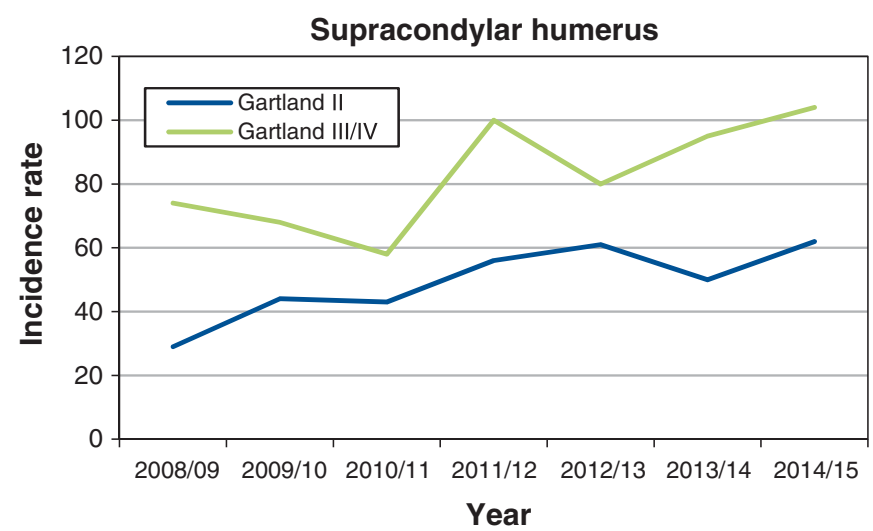

C) Stratified by season

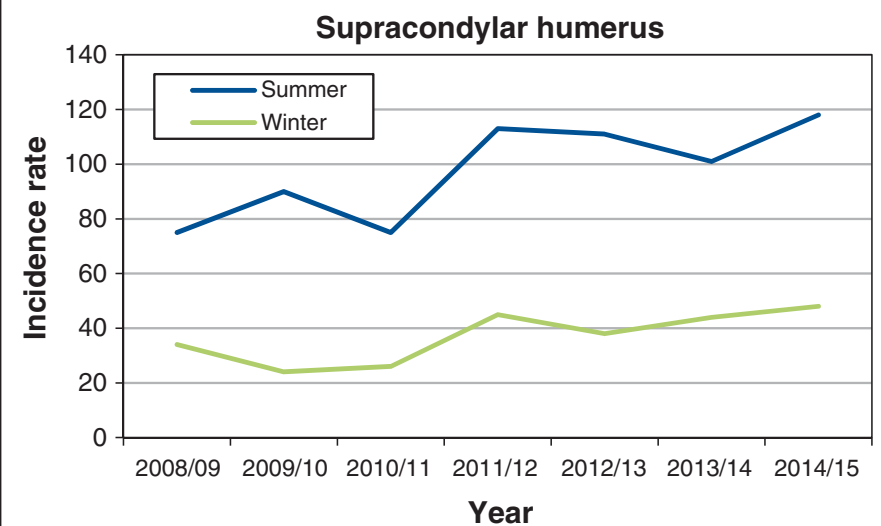

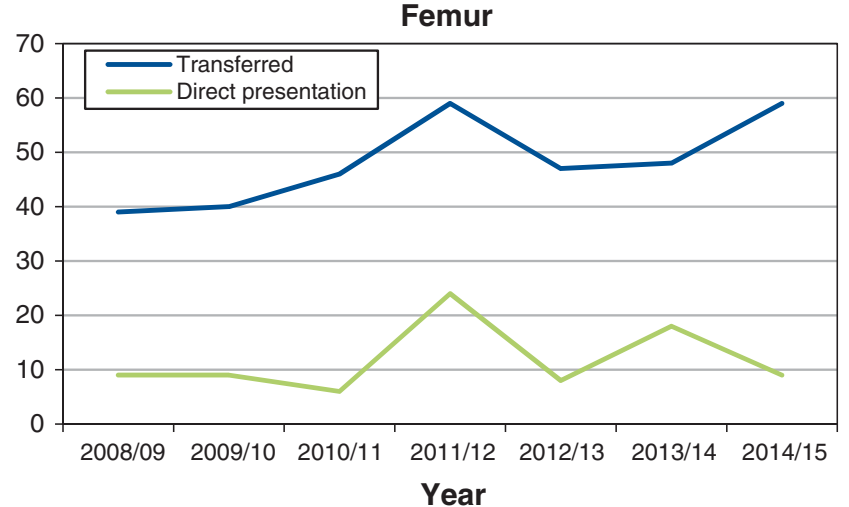
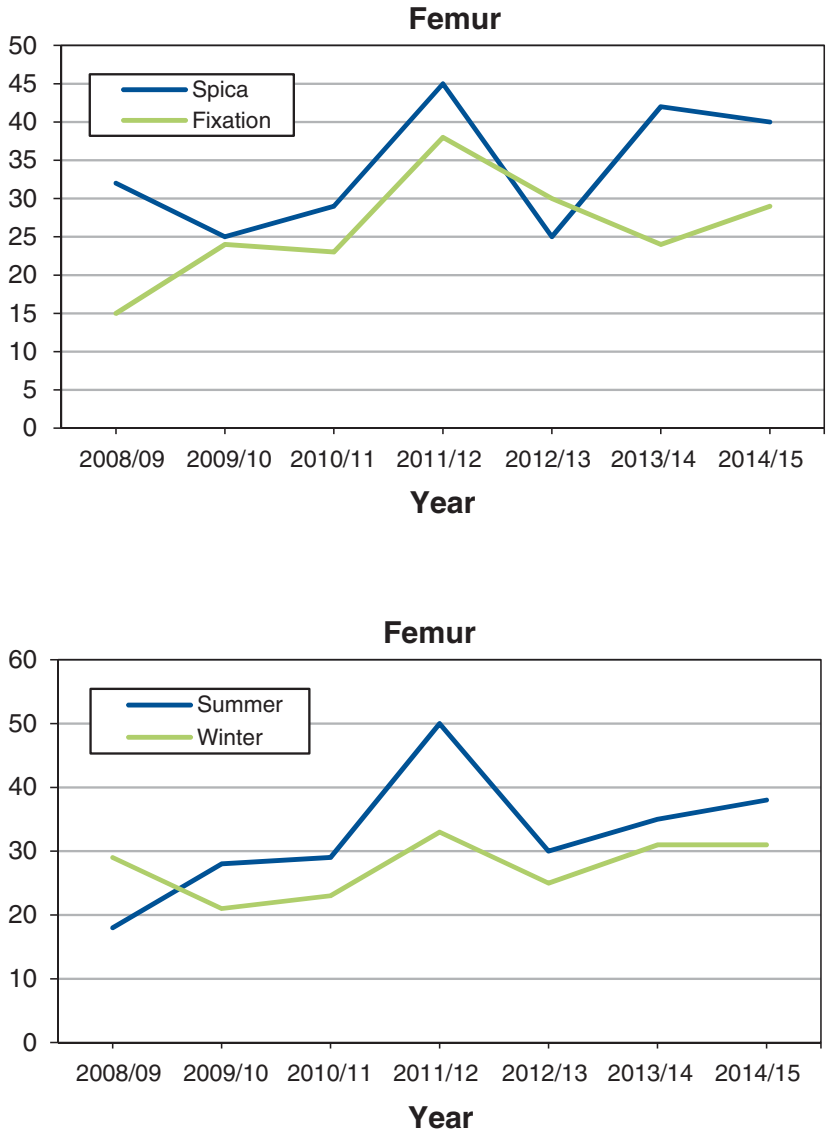

Figure 4: Population-standardized annual incidence rates of uncomplicated supracondylar humerus and femur fractures, 2008/09 to 2014/15, by patient subgroup. Rates standardized to the Greater Toronto Area population aged 14 years or less in 2011.

occurring in the Greater Toronto Area for pediatric fracture care, its effect on clinical outcomes and costs is unclear. Further work is needed to assess the clinical impact of informal regionalization of care, to determine whether the phenomenon is found in other specialties and to understand why it is occurring.

\section{References}

1. Escott B. Childhood fracture begets childhood fracture: a population-based study of longitudinal fracture patterns in Ontario children [master's thesis]. Toronto: University of Toronto; 2012.

2. Objectives of training in the specialty of orthopaedic surgery. Ottawa: Royal College of Physicians and Surgeons of Canada; 2010.

3. Urbach DR. Pledging to eliminate low-volume surgery. N Engl 7 Med 2015; 373:1388-90. 
4. Lewis S, Kouri D. Regionalization: making sense of the Canadian experience. Healthc Pap 2004;5:12-31.

5. Block EF, Rudloff B, Noon C, et al. Regionalization of surgical services in central Florida: the next step in acute care surgery. 7 Trauma 2010;69:640-3.

6. Collier R. Is regionalization working? CMA7 2010;182:331-2

7. Finley C, Schneider L, Shakeel S. Approaches to high-risk, resource intensive cancer surgical care in Canada. Toronto: Canadian Partnership Against Cancer; 2015.

8. Heng $M$, Wright JG. Dedicated operating room for emergency surgery improves access and efficiency. Can 7 Surg 2013;56:167-74.

9. Khoshbin A, Leroux T, Wasserstein D, et al. The epidemiology of paediatric supracondylar fracture fixation: a population-based study. Injury 2014;45:701-8.

10. Barton KL, Kaminsky CK, Green DW, et al. Reliability of a modified Gartland classification of supracondylar humerus fractures. F Pediatr Orthop 2001;21:27-30.

11. Cowan JA Jr, Dimick JB, Henke PK, et al. Surgical treatment of intact thoracoabdominal aortic aneurysms in the United States: hospital and surgeon volumerelated outcomes. 7 Vasc Surg 2003;37:1169-74.

12. Hu JC, Gold KF, Pashos CL, et al. Role of surgeon volume in radical prostatectomy outcomes. 7 Clin Oncol 2003;21:401-5.

13. Lieberman MD, Kilburn H, Lindsey M, et al. Relation of perioperative deaths to hospital volume among patients undergoing pancreatic resection for malignancy. Ann Surg 1995;222:638-45.

14. Simunovic M, To T, Theriault M, Langer B. Relation between hospital surgical volume and outcome for pancreatic resection for neoplasm in a publicly funded health care system. CMA7 1999;160:643-8.

15. Ravi B, Jenkinson R, Austin PC, et al. Relation between surgeon volume and risk of complications after total hip arthroplasty: propensity score matched cohort study. BM7 2014;348:g3284.

16. Stavrakis AI, Ituarte PH, Ko CY, et al. Surgeon volume as a predictor of outcomes in inpatient and outpatient endocrine surgery. Surgery 2007;142:887-99.

17. Poeze M, Verbruggen JPAM, Brink PRG. The relationship between the outcome of operatively treated calcaneal fractures and institutional fracture load. $\mathcal{F}$ Bone foint Surg Am 2008;90:1013-21.

18. Sahni NR, Dalton M, Cutler DM, et al. Surgeon specialization and operative mortality in United States: retrospective analysis. BM7 2016;354:13571-90.

19. Ibrahim T, Hegazy A, Abulhail SI, et al. Utility of the AAOS appropriate use criteria (AUC) for pediatric supracondylar humerus fractures in clinical practice. 7 Pediatr Orthop 2017;37:14-19

20. Mulpuri K, Hosalkar H, Howard A. AAOS clinical practice guideline: the treatment of pediatric supracondylar humerus fractures. 7 Am Acad Orthop Surg 2012;20:328-90.

21. Kasser JR. Location of treatment of supracondylar fractures of the humerus in children. Clin Orthop Relat Res 2005;May:110-3.
22. Loizou CL, Simillis C, Hutchinson JR. A systematic review of early versus delayed treatment for type III supracondylar humeral fractures in children. Injury 2009;40:245-8.

23. The Hospital for Sick Children strategic plan 2015 to 2020. Toronto: SickKids; 2015. Available: https://www.sickkids.ca/pdfs/About-SickKids/65498-The\% 20Hospital\%20for\%20Sick\%20Children\%20Strategic\%20Plan \%202015 -2020.pdf (accessed 2017 June 7).

Affiliations: Division of Orthopaedic Surgery (Pincus, Gargan, Camp) Department of Surgery, University of Toronto; Institute for Clinical Evaluative Sciences (Pincus); Institute of Health Policy, Management and Evaluation (Pincus), University of Toronto; The Hospital for Sick Children (Morrison, Gargan, Camp), Toronto, Ont.

Contributors: All of the authors conceived and designed the study, acquired, analyzed and interpreted the data, drafted and revised the manuscript, approved the final version to be published and agreed to act as guarantors of the work.

Funding: This study was supported by internal funding from the Department of Orthopaedic Surgery, Hospital for Sick Children. No benefits have been received or will be received from a commercial party related directly or indirectly to the subject of this article.

Acknowledgements: The authors sincerely thank Alex Uren and Hannah Matthews for their help with data collection and Peter Godzyra for creating the maps. The authors also thank James Wright, Nizar Mahomed, Amir Khoshbin, David Wasserstein and Michael Paterson for their help in obtaining relevant data from the Institute for Clinical Evaluative Sciences.

Disclaimer: This study was supported by the Institute for Clinical Evaluative Sciences (ICES), which is funded by an annual grant from the Ontario Ministry of Health and Long-Term Care (MOHLTC). The opinions, results and conclusions reported in this article are those of the authors and are independent from the funding sources. No endorsement by the ICES or the Ontario MOHLTC is intended or should be inferred.

Supplemental information: For reviewer comments and the original submission of this manuscript, please see www.cmajopen.ca/content/5/2/ E468/suppl/DC1 